\title{
Aplikasi Prediksi Kelayakan Calon Anggota Kredit Menggunakan Algoritma Naïve Bayes
}

\author{
Diky Alfian Kurniawan'), Yogiek Indra Kurniawan²) \\ Program Studi Informatika, Fakultas Komunikasi dan Informatika \\ Universitas Muhammadiyah Surakarta ${ }^{1,2}$ \\ dikyalfian19@gmail.com,yogiek@ums.ac.id ${ }^{1,2)}$
}

\begin{abstract}
As a financial institution other than a conventional bank, the coorperative has a role to play in overcoming the economy of the people in the regions. The event was also carried out by the Saving and Loans Cooperative Baitul Maal wa Tamwil (KSPPS BMT) "Arta Jiwa Mandiri" Wonogiri which is engaged in syariah credit and saving credit business. On proses of credit cooperative saving business cooperative have provisions in choosing a worthy member candidate to be given capital. It aims to overcome the problems such as member stuck in instalment payments. So it is necessary for an application that can prediction prospective credit members who are eligible to get loans from the cooperative with data mining techniques. Nä̈ve Bayes algorithm is used in this case to predict the feasibility of prospective members of credit and savings loan which will include the current category, substandard or loss of time borrowing. The result of this research get Accuracy value equal to $80 \%$, Precision value equal to $82 \%$ and Recall value equal to $94 \%$. Therefore, this application can assist the cooperative in considering the prospective members of a decent credit to get capital.
\end{abstract}

Keywords: data mining. nä̈ve bayes, savings and loans, cooperatives.

\section{PENDAHULUAN}

Meningkatnya perekonomian saat ini membuat banyaknya pengeluaran yang harus ditanggung oleh setiap orang yang ada dimuka bumi ini. Kebutuhan yang semakin hari semakin banyak dan membuat setiap orang membutuhkan biaya dalam mencukupi kebutuhan sehari-hari maupun biaya untuk menjalankan usahanya agar tetap berjalan terus. Semua permasalahan tersebut dapat diatasi oleh lembaga koperasi yang dapat membantu dalam memberikan pinjaman. Lembaga koperasi memiliki banyak bidang usaha yaitu salah satunya kredit simpan pinjam. Koperasi simpan pinjam mendapatkan modal dari hasil pemupukan simpanan dari anggotanya, dan nantinya akan dipinjamkan kembali kepada anggota yang membutuhkan modal

[1].Adapun Koperasi Simpan Pinjam dan Pembiayaan Syariah Baitul Maal wa Tamwil
(KSPPS BMT) “Arta Jiwa Mandiri” Wonogiri, merupakan suatu lembaga koperasi yang bergerak dalam pelayanan kredit simpan pinjam berbasis syariah. Pada proses menjalankan usaha kredit simpan pinjam koperasi memiliki aturan yang sudah ditetapkan dalam menentukan calon anggota kredit simpan pinjam. Aturan tersebut bertujuan untuk mengurangi adanya permasalahan seperti penunggakan dalam pelunasan cicilan. Berdasarkan permasalahan tersebut diperlukan suatu aplikasi yang dapat memprediksi calon anggota kredit yang layak mendapatkan modal usaha.

Penggunaan algoritma Nä̈ve Bayes telah banyak digunakan dalam berbagai kasus penelitian untuk memprediksi suatu permasalahan. Mahboob, dkk menggunakan berbagai metode data mining dalam penelitianya dan salah satunya menggunakan algoritma Nä̈ve Bayes [2]. Penelitian ini membahas mengenai pembelajaran siswa menggunakan 
machine learning. Tujuan dari penelitian ini untuk memprediksi keberhasilan siswa dalam pembelajaran menngunakan machine learning. Hasilnya akan diketahui siswa tersebut lulus atau gagal dalam metode pembelajaran tersebut. Tujuan adanya aplikasi tersebut yaitu sebagai panduan dan evaluasi kinerja dimasa yang akan datang.

Octabriyantiningtyas dalam penelitiannya pada Bank Tabungan Negara (BTN) mengenai pengambilan keputusan dalam pemberian kredit [3]. Tujuan penelitian yaitu untuk menganalisa dan menentukan nasabah yang layak mendapatkan kredit. Metode yang diterapkan dalam penelitian yaitu menggunakan algoritma C4.5 sebagai proses perhitungannya. Kesimpulan yang diperoleh yaitu dengan menggunakan algoritma C4.5 dapat menyelesaikan masalah dalam menentukan calon nasabah kredit yang berhak mendapatkan kredit dari BTN dengan output berupa pohon keputusan dengan informasi layak atau tidak layak. Rata-rata nilai akurasi yang diperoleh $65,50 \%$ dan nilai deviasi 5,126 .

Jumadi, dkk pada penelitiannya membahas mengenai sistem pendukung keputusan pemberian kredit rumah sejahtera pada nasabah Bank Pembangunan Daerah (BPD) Kalimantan Timur [4]. Penelitian ini menggunakan metode Technique For Order Preference by Similitary To Ideal Solution (TOPSIS). Kesimpulan dari penelitian tersebut yaitu menggunakan metode TOPSIS dapat menentukan nasabah yang berhak mendapatkan kredit rumah sejahtera yang tepat dan sesuai dengan kriteria dari pihak Bank. Dengan memperhitungkan solusi ideal positif dan nilai terjauh solusi negatif.

Kurniawan mengembangkan suatu aplikasi pendukung keputusan dengan menggunakan metode Simple Additive Weighting (SAW) yang berfokus pada permasalahan mengenai penyeleksian beasiswa yang ada di perguruan tinggi [5]. Tujuan penelitian ini yaitu saat penyeleksian beasiswa di perguruan tinggi agar hasil seleksi yang diperoleh tidak bersifat subjective.

Berdasarkan analisa dari penelitian terdahulu maka terdapat perbedaan dalam penggunaan metode pada penelitian ini. Penelitian yang dilakukakan pada KSPPS BMT “Arta Jiwa Mandiri” Wonogiri mengenai aplikasi prediksi kelayakan calon anggota kredit simpan pinjam yaitu menggunakan metode data mining dengan algoritma Nä̈ve Bayes. Data yang digunakan dalam penelitian ini keseluruhannya diperoleh dari riwayat anggota kredit simpan pinjam di koperasi tersebut. Tujuan adanya aplikasi ini untuk membantu pihak koperasi dalam menganalisa calon anggota kredit yang mengajukan pinjaman dengan mengetahui hasil output dari aplikasi berupa kategori lancar, kurang lancar dan macet. Menurut Nugroho penggunaan algoritma Nä̈ve Bayes dapat memprediksi suatu permasalahan dengan membandingkan nilai probabilitas pada data training [6].

\section{METODE PENELITIAN}

\subsection{Metodologi Penelitian}

Metodologi penelitian yang digunakan dalam penelitian ini menggunakan beberapa tahapan mulai dari analisis masalah, pengumpulan data, desain, implementasi, pengujian, analisis hasil sampai ke tahap kesimpulan dan saran, seperti gambar 1 berikut: 


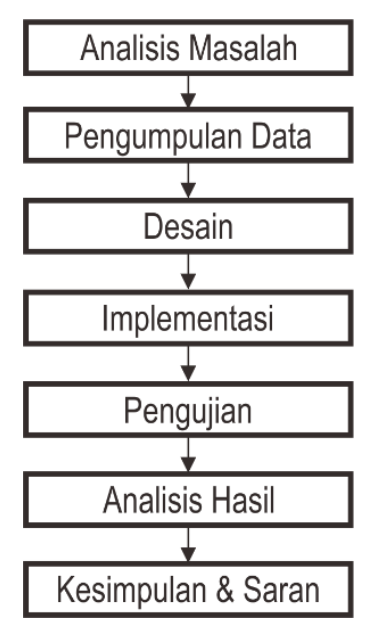

Gambar 1. Bagan tahapan penelitian

\subsection{Analisis Masalah}

Tahap analisis masalah pada penelitian ini yaitu mengenai calon anggota kredit simpan pinjam yang mengajukan permohonan pinjaman. Pihak koperasi harus memilih calon anggota kredit yang layak untuk mendapatkan pinjaman dan calon anggota kredit tersebut nantinya tidak memiliki potensi penunggakan dalam pelunasan cicilan. Kesimpulan dari analisis masalah tersebut maka diperlukan suatu aplikasi yang dapat memprediksi kelayakan calon anggota kredit simpan pinjam yang sesuai dengan ketentuan dari pihak koperasi.

\subsection{Pengumpulan Data}

Penelitian ini menggunakan data dari kantor pusat KSPPS BMT “Arta Jiwa Mandiri” Wonogiri. Data pada penelitian dibagi menjadi 2 kelompok sesuai dengan pembagiannya.

\subsubsection{Kebutuhan Data}

Proses dalam menentukan kebutuhan data diperlukan dalam metode data mining ini. Pada Data training dan testing datanya dikelompokkan menurut nilai atribut yang sesuai dengan kebutuhan penelitian agar hasil yang diperoleh sesuai dengan yang diharapkan. Pengelompokan atribut-atribut sesuai dengan yang disajikan pada tabel 1 berikut:

Tabel 1. Atribut dalam prediksi calon anggota kredit simpan pinjam

\begin{tabular}{|l|l|l|l|}
\hline \multicolumn{1}{|c|}{ Atribut } & \multicolumn{1}{|c|}{ Tipe } & \multicolumn{1}{|c|}{ Keterangan } & Variabel \\
\hline Jenis Kelamin & Binomial & Laki-Laki (L) dan Perempuan (P) & X1 \\
\hline Umur & Polinomial & $19-24$ & $\mathrm{X} 2$ \\
& & $25-30$ & \\
& & $31-36$ & \\
& & $37-42$ & \\
& & $43-48$ & \\
& & $49-54$ & \\
\hline Jenis Pekerjaan & Polinomial & Wiraswasta, Swasta, Ibu rumah tangga, dan & $\mathrm{X} 3$ \\
& & PNS & \\
\hline Jumlah Pinjaman & Polinomial & $1.000 .000-1.999 .999$ & $\mathrm{X} 4$ \\
& & $2.000 .000-2.999 .999$ & \\
& & $3.000 .000-4.999 .999$ & \\
& & $5.000 .000-6.999 .999$ & \\
& & $7.000 .000-9.999 .999$ & \\
& & $10.000 .000-12.999 .999$ & \\
& & $13.000 .000-14.999 .999$ & \\
& & $15.000 .000-19.999 .999$ & \\
& & $20.0000 .0000-24.999 .999$ & \\
& & $25.000 .000-29.999 .999$ & \\
& & &
\end{tabular}




\begin{tabular}{|c|c|c|c|}
\hline & & $\begin{array}{l}30.000 .000-49.999 .999 \\
50.000 .000-79.999 .999 \\
80.000 .000-109.999 .999 \\
110.000 .000-139.999 .999 \\
140.000 .000-169.999 .999 \\
170.000 .000-200.000 .000\end{array}$ & \\
\hline $\begin{array}{l}\text { Jangka Waktu } \\
\text { Pengembalian }\end{array}$ & Polinomial & $\begin{array}{l}1 \text { sampai dengan } 12 \text { bulan = Pendek } \\
13 \text { sampai dengan } 36 \text { bulan = Menengah } \\
\text { Lebih dari } 36 \text { bulan = Panjang }\end{array}$ & $\mathrm{X} 5$ \\
\hline Jaminan & Polinomial & BPKP Motor, BPKB Mobil, Sertivikat & X6 \\
\hline Penghasilan & Polinomial & 1 - 5 Juta, 6 - 10 Juta, dan Lebih dari 11 Juta & $\mathrm{X} 7$ \\
\hline Kategori & Label & Lancar, Kurang Lancar, dan Macet & $\mathrm{Y}$ \\
\hline
\end{tabular}

\subsubsection{Pembersihan Data}

Sebelum melakukan proses pengolahan data mining maka diperlukan pembersihan data terlebih dahulu, pembersihan tersebut bertujuan untuk menyesuaikan data dengan kebutuhan aplikasi. Pada proses pembersihan data maka data disesuaikan dengan atribut-atribut yang akan dibutuhkan dalam pemrosesan pada aplikasi, sehingga terhindar dari ketidakkonsistenan data.

\subsection{Desain}

Untuk menjelaskan fungsi kebutuhan aplikasi yang dibuat maka akan digambarkan suatu rancangan aplikasi secara menyeluruh berupa use case diagram. Keseluruhan fungsi yang dapat digunakan pada aplikasi ini meliputi: pengguna dapat menambahkan data testing maupun training, menghapus data, melihat data ataupun pengguna dapat mengubah informasi data. Use case dapat dilihat gambar 2.

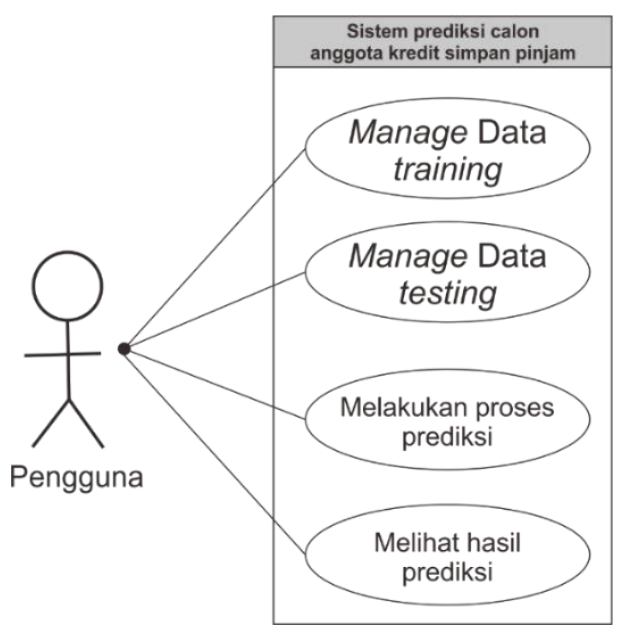

Gambar 2. Use case diagram pengguna

\subsection{Implementasi}

Implementasi merupakan proses penerapan terhadap hasil analisis masalah yang akan diselesaikan. Pada proses implementasi penelitian ini, akan diterapkan dalam pembuatan suatu aplikasi.

\subsubsection{Penerapan Algoritma Nä̈ve Bayes}

Jadhav dalam penelitiannya berpendapat tentang Nä̈ve Bayes Classifier yaitu suatu model independen yang membahas mengenai klasifikasi sederhana berdasarkan teorema Bayes [7]. Nä̈ve Bayes merupakan suatu algoritma yang dapat 
mengklasifikasikan suatu variable tertentu dengan menggunakan metode probabilitas dan statistic menurut Haryati [8]. Secara garis besar algoritma Nä̈ve Bayes menurut Bustami [9] seperti persamaan (1).

$$
P(R \mid S)=\frac{P(R) P(S \mid R)}{P(S)}
$$

\section{Keterangan:}

R : Data yang belum diketahui kelasnya

$\mathrm{S} \quad$ : Hipotesis pada data $\mathrm{R}$ yang merupakan class khusus

$P(R \mid S)$ : Nilai probabilitas pada hipotesis $R$ yang berdasarkan kondisi $S$
$P(R)$ : Nilai probabilitas pada hipotesi $R$ $P(S \mid R)$ : Nilai probabilitas $S$ yang berdasarkan dengan kondisi hipotesis $R$

$P(S) \quad$ : Nilai probabilitas pada

Algoritma Nä̈ve Bayes digunakan menghitung perbandingan probabilitas dari masing-masing atribut pada setiap data training. Tabel 2 dan 3 berikut merupakan contoh perhitungan menggunakan algoritma Nä̈ve Bayes dengan mengambil 10 data sebagai data training dan 1 data sebagai data testing.

Tabel 2. Contoh data training

\begin{tabular}{|c|c|c|c|c|c|c|c|c|}
\hline Nama & $\begin{array}{c}\text { Jenis } \\
\text { Kelamin }\end{array}$ & Umur & Jenis Pekerjaan & Jumlah Pinjaman & $\begin{array}{c}\text { Jangka Waktu } \\
\text { Pengembalian }\end{array}$ & Jaminan & Penghasilan & Kategori \\
\hline SUTIYEM & $\mathrm{P}$ & $37-42$ & Wiraswasta & $5000000-6999999$ & Menengah & BPKB Motor & $<5$ Juta & Macet \\
\hline KARSANTO & L & $43-48$ & PNS & $2000000-2999999$ & Pendek & BPKB Mobil & 5 - 10 Juta & Lancar \\
\hline SURANTO & L & $31-36$ & Swasta & $5000000-6999999$ & Menengah & BPKB Motor & $<5$ Juta & Macet \\
\hline TARJO HARSONO & L & $55-60$ & PNS & $10000000-12999999$ & Menengah & Sertivikat & $<5$ Juta & Lancar \\
\hline KUSDIYATMINI & P & $43-48$ & Ibu Rumah Tangga & $7000000-9999999$ & Menengah & BPKB Motor & $<5$ Juta & Lancar \\
\hline SUWARTI & P & $37-42$ & Ibu Rumah Tangga & $5000000-6999999$ & Menengah & BPKB Motor & $<5$ Juta & Lancar \\
\hline TITIK SUYANTI & P & $31-36$ & Wiraswasta & $25000000-29999999$ & Pendek & BPKB Motor & $<5$ Juta & Lancar \\
\hline PARNO & L & $55-60$ & Wiraswasta & $10000000-12999999$ & Menengah & Sertivikat & $<5$ Juta & Lancar \\
\hline ISWADI & L & $37-42$ & Wiraswasta & $15000000-19999999$ & Menengah & Sertivikat & $<5$ Juta & Lancar \\
\hline RANTI & P & $37-42$ & Wiraswasta & $10000000-12999999$ & Menengah & Sertivikat & $<5$ Juta & Kurang Lancar \\
\hline
\end{tabular}

Tabel 3. Contoh data testing

\begin{tabular}{|c|c|c|c|c|c|c|c|c|}
\hline Nama & $\begin{array}{c}\text { Jenis } \\
\text { Kelamin }\end{array}$ & Umur & Jenis Pekerjaan & Jumlah Pinjaman & $\begin{array}{c}\text { Jangka Waktu } \\
\text { Pengembalian }\end{array}$ & Jaminan & Penghasilan & Kategori \\
\hline Suratmi & $\mathrm{P}$ & $55-60$ & Wiraswasta & $25000000-29999999$ & Menengah & Sertivikat & $<5$ Juta & $?$ \\
\hline
\end{tabular}

Perhitungan algoritma Nä̈ve Bayes pada tabel 3 sebagai berikut.

$\mathrm{P}(\mathrm{Y}=$ Lancar $)=7 / 10=0,7$

$\mathrm{P}(\mathrm{Y}=$ Kurang Lancar $)=1 / 10=0,1$

$\mathrm{P}(\mathrm{Y}=$ Macet $)=2 / 10=0,2$

Mencari nilai probabilitas pada tiap atribut

$\mathrm{P}($ Jenis Kelamin $=\mathrm{P} \mid \mathrm{Y}=$ Lancar $)=3 / 7=0,428$

$\mathrm{P}($ Umur $=55-60 \mid \mathrm{Y}=$ Lancar $)=2 / 7=0,285$
$\mathrm{P}($ Jenis Pekerjaan $=$ Wiraswasta $\mid \mathrm{Y}=$ Lancar $)=3 / 7$ $=0,428$

$\mathrm{P}($ Jenis Pinjaman $=20000000-29999999 \mid \mathrm{Y}=$ Lancar) $=1 / 7=0,142$

$\mathrm{P}($ Jangka waktu pengembalian $=$ Menengah $\mid \mathrm{Y}=$ Lancar) $=5 / 7=0,714$

$\mathrm{P}($ Jaminan $=$ Sertivikat $\mid \mathrm{Y}=$ Lancar $)=3 / 7=0,428$

$\mathrm{P}($ Penghasilan $=<5$ Juta $\mid \mathrm{Y}=$ Lancar $)=6 / 7=0,857$

$\mathrm{P}($ Jenis Kelamin $=\mathrm{L} \mid \mathrm{Y}=$ Kurang Lancar $)=1 / 1=1$ 
$\mathrm{P}($ Umur $=55-60 \mid \mathrm{Y}=$ Kurang Lancar $)=0 / 1=0$

$\mathrm{P}$ (Jenis Pekerjaan $=$ Wiraswasta $\mid \mathrm{Y}=$ Kurang

Lancar) $=0 / 1=0$

$\mathrm{P}($ Jenis Pinjaman $=20000000-29999999 \mid \mathrm{Y}=$

Kurang Lancar) $=0 / 1=0$

$\mathrm{P}$ (Jangka waktu pengembalian $=$ Menengah $\mid \mathrm{Y}=$

Kurang Lancar) $=1 / 1=1$

$\mathrm{P}($ Jaminan $=$ Sertivikat $\mid \mathrm{Y}=$ Kurang Lancar $)=1 / 1$

$=1$

$\mathrm{P}($ Penghasilan $=<5$ Juta $\mid \mathrm{Y}=$ Kurang Lancar $)=1 / 1$

$=1$

$\mathrm{P}($ Jenis Kelamin $=\mathrm{L} \mid \mathrm{Y}=$ Macet $)=3 / 2=1,5$

$\mathrm{P}($ Umur $=55-60 \mid \mathrm{Y}=$ Macet $)=0 / 2=0$

$\mathrm{P}($ Jenis Pekerjaan $=$ Wiraswasta $\mid \mathrm{Y}=$ Macet $)=0 / 2$ $=0$

$\mathrm{P}($ Jenis Pinjaman $=2000000-29999999 \mid \mathrm{Y}=$ Macet $)=0 / 2=0$

$\mathrm{P}($ Jangka waktu pengembalian $=$ Menengah $\mid \mathrm{Y}=$ Macet) $=2 / 2=1$

$\mathrm{P}($ Jaminan $=$ Sertivikat $\mid \mathrm{Y}=$ Macet $)=0 / 2=0$

$\mathrm{P}($ Penghasilan $=<5$ Juta $\mid \mathrm{Y}=$ Macet $)=2 / 2=1$

Menghitung hasil dari atribut lancar, kurang lancar, dan macet

$\mathrm{P}($ Kategori $=$ Lancar $) * \mathrm{P}(\mathrm{Y}=$ Lancar $)=0,00135$

$\mathrm{P}$ (Kategori $=$ Kurang Lancar) $* \mathrm{P}(\mathrm{Y}=$ Kurang Lancar $)=0$

$\mathrm{P}($ Kategori $=$ Macet $) * \mathrm{P}(\mathrm{Y}=$ Macet $)=0$

Kesimpulan hasil yang diperoleh dari perhitungan menunjukan bahwa masukan pada tabel 3 menghasilkan ( $\mathrm{P}=$ Lancar) dengan hasil probabilitas tertinggi.
2.5 Pengujian

Pengujian yang dilakukan pada implementasi aplikasi dengan memperhitungkan tingkat precision, recall, dan accuracy [10]. Maka dijelaskan seperti persamaan (2), (3) dan 4 sebagai berikut:

Pengujian precision digunakan dalam mencari nilai proporsi kasus positif yang benar, rumus persamaan (2).

$$
\text { Precision }=\frac{\mathrm{TP}}{\mathrm{TP}+\mathrm{FP}}
$$

Pengujian recall digunakan dalam mencari nilai proporsi kasus positif yang teridentifukasi benar, rumus persamaan (3).

$$
\text { Recall }=\frac{\mathrm{TP}}{\mathrm{TP}+\mathrm{FN}}
$$

Pengujian accuracy digunakan dalam mencari nilai proporsi jumlah yang benar, rumus persamaan (4).

$$
\text { accuracy }=\frac{\mathrm{TP}+\mathrm{TN}}{\mathrm{TP}+\mathrm{FP}+\mathrm{TN}+\mathrm{FN}}
$$

Keterangan:

TP : True Positive

TN : True Negative

FP : False Positive

FN : False Negative

\section{HASIL DAN PEMBAHASAN}

\subsection{Hasil Implementasi}

Tahap ini merupakan tahap dimana aplikasi yang dibuat telah selesai dibuat, untuk menjalankan aplikasi ini menggunakan server local di komputer untuk mengetahui hasilnya.

\subsubsection{Halaman login}

Saat membuka aplikasi prediksi kelayakan calon anggota kredit maka pengguna wajib memasukkan username dan password bertujuan untuk masuk 
dalam aplikasi, maka tampilan awal seperti yang dilihat pada gambar 3 .

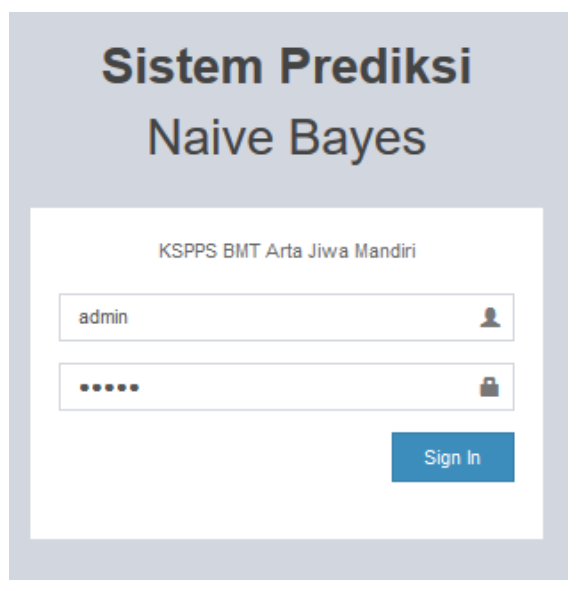

Gambar 3. Halaman login pengguna

\subsubsection{Halaman beranda}

Halaman ini akan tampil setelah pengguna melakukan proses login, pada halaman ini pengguna dapat memilih beberapa menu yang dapat langsung diakses berupa menu data training, menu data testing dan pengguna dapat langsung logout dari sistem.

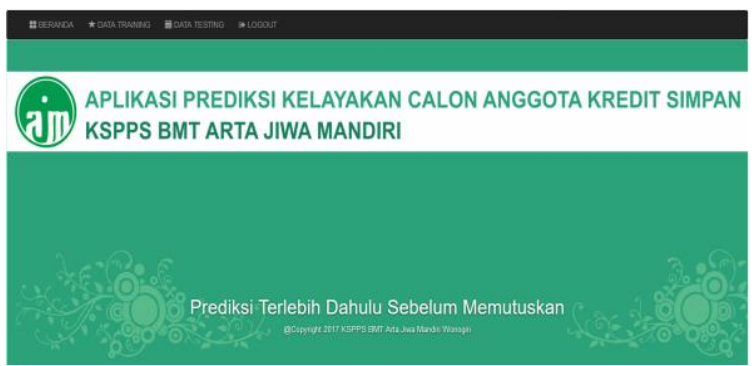

Gambar 3. Halaman beranda

\subsubsection{Halaman data training}

Data training sangat dibutuhkan pada metode data mining dimana data tersebut digunakan sebagai dasar pembanding pada masukan didata testing. Pada halaman data training setiap datanya terdapat fitur ubah dan hapus. Gambar 4 menunjukkan antarmuka halaman data

training.

\section{HBERANDA $\star$ DATATRANING EDATA TESTING ELOGOUT}

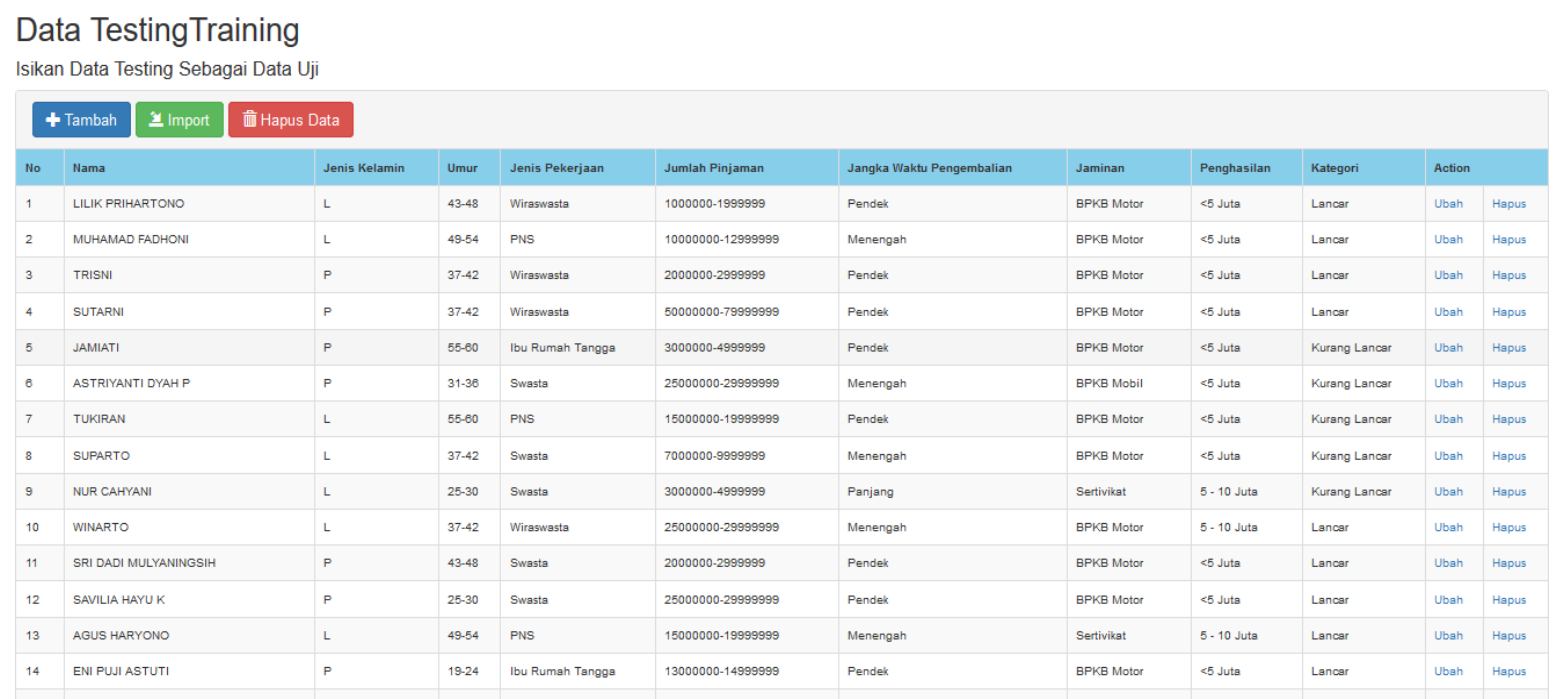

\subsubsection{Halaman tambah data training}

Halaman ini yaitu pengguna diharuskan mengisi form yang lengkap sesuai dengan kebutuhan data pada data training. Pada form ini data harus diisi semua dan jika ada data tidak terisi maka data tidak akan bisa disimpan. 


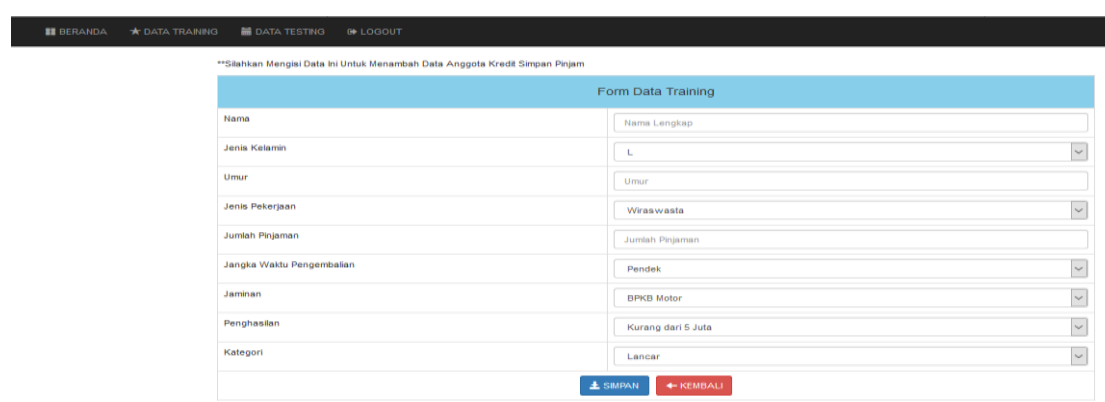

Gambar 5. Halaman tambah data training

\subsubsection{Halaman data testing}

Data testing merupakan masukkan yang akan dicari hipotesisnya atau pada aplikasi ini data testing digunakan untuk memprediksi calon anggota kredit simpan pinjam dengan berdasarkan pada data training. Fitur ubah dan hapus terdapat pada setiap data. Gambar 6 menampilkan antar muka halaman data testing.

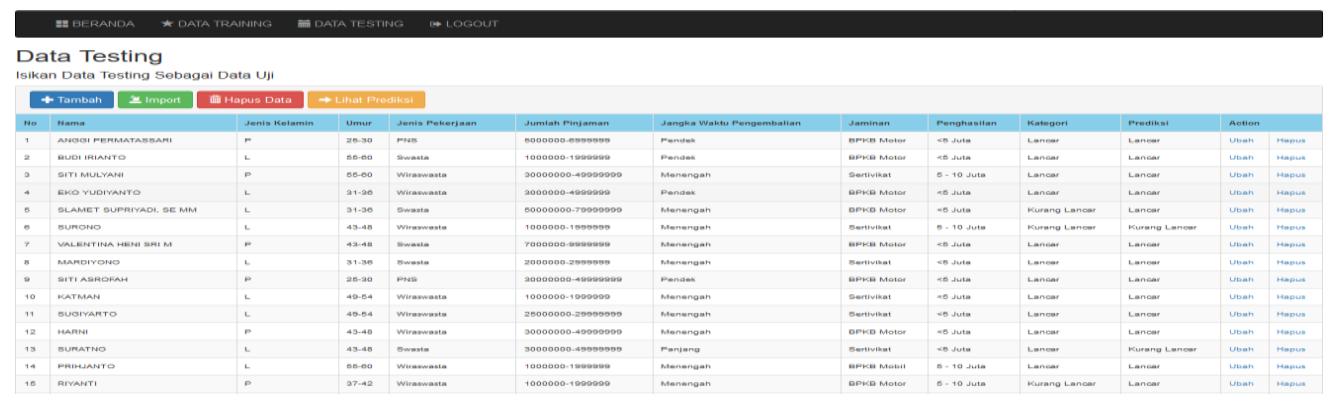

Gambar 6. Halaman data testing

3.1.6 Halaman tambah data training

Halaman ini pengguna mengisi form untuk memasukkan data testing dan bertujuan untuk mengetahui hasil prediksi yang berdasarkan data training.

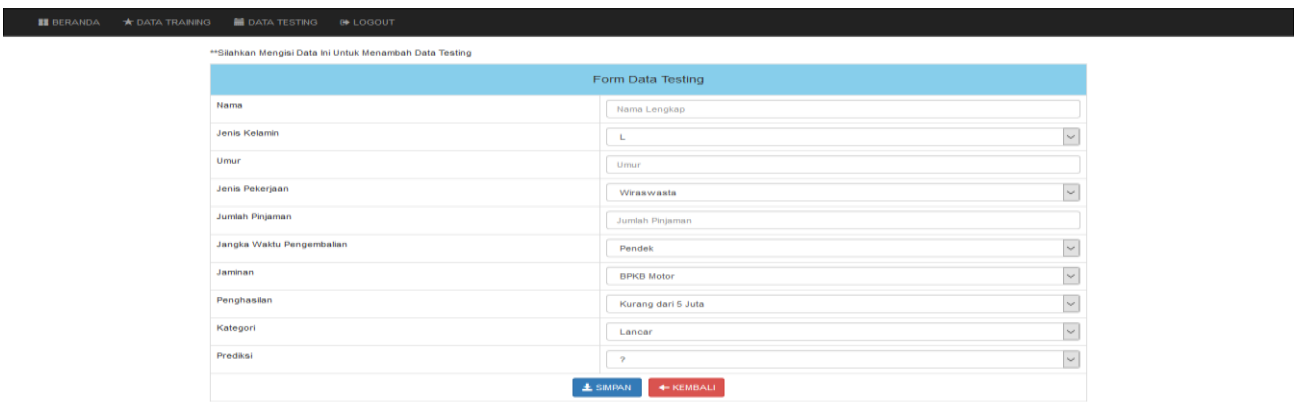

Gambar 7. Halaman tambah data testing

\subsubsection{Halaman lihat prediksi}

Algoritma Naïve Bayes digunakan pada penelitian ini untuk memprediksi suatu permasalahan dan akan menghasilkan hipotesis atau kesimpulan. Pada aplikasi ini proses tersebut dapat langsung diketahui rincian perhitungannya. Halaman ini akan tampil jika pengguna sebelumnya memasukkan data training dan data testing maka halaman lihat prediksi akan dapat diketahui hasil prediksinya seperti gambar 7. Pada halaman tersebut setiap data terdapat 
fitur detail yang berfungsi untuk melihat urutan seperti gambar 8 .

perhitungan sesuai dengan algoritma Nä̈ve Bayes

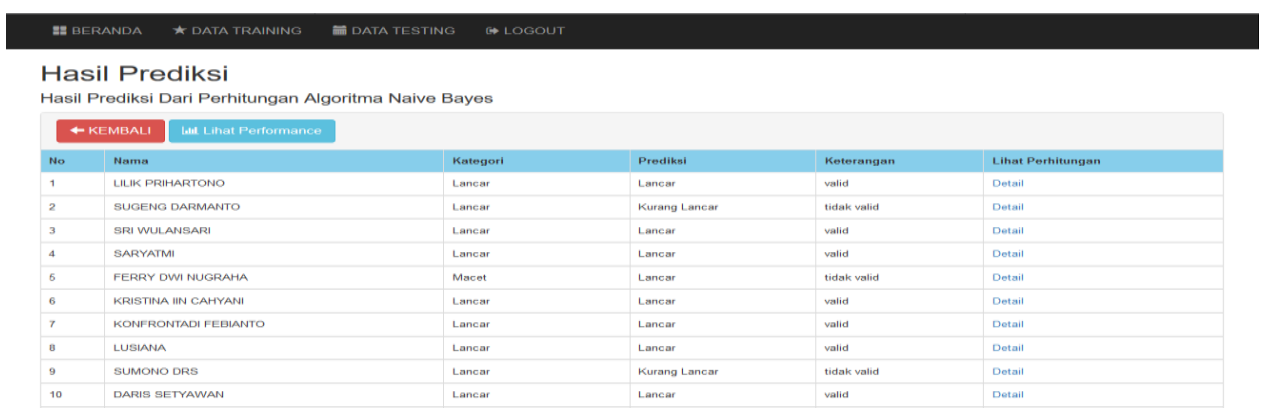

Gambar 7. Halaman lihat prediksi

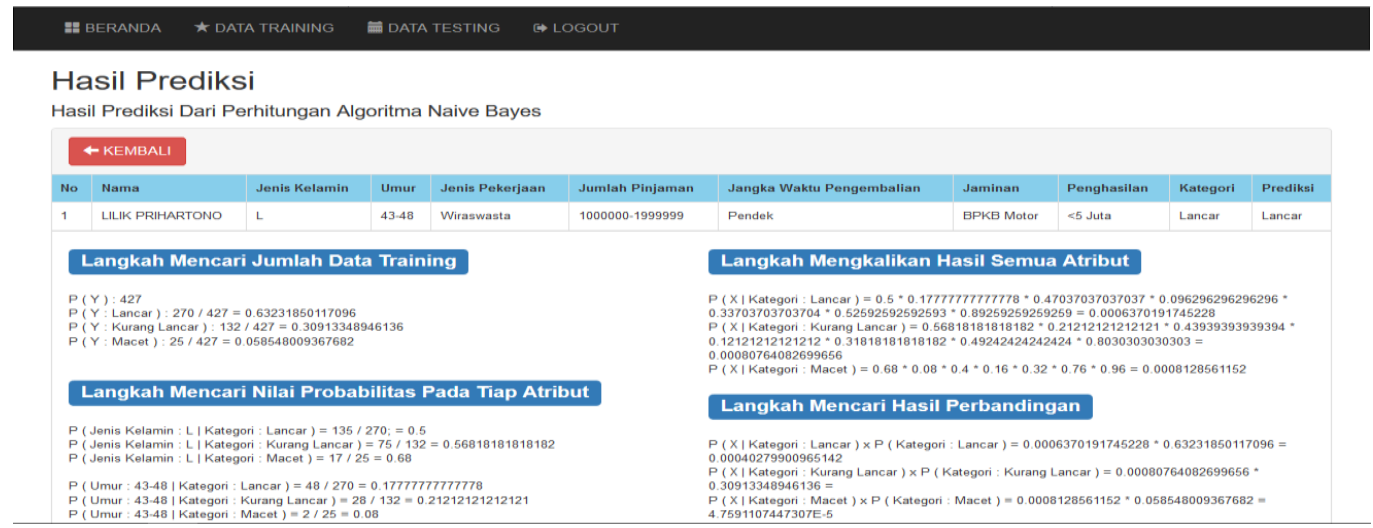

Gambar 8. Halaman detail perhitungan Naïve Bayes

3.1.8 Halaman lihat performance

Halaman lihat performance yang muncul setelah pengguna memilih fitur lihat prediksi. Pada halaman ini yaitu menampilkan hasil accuracy, precision dan recall dari keseluruhan data yang ada pada data testing. Pengguna dapat langsung melihat jumlah True Positive (TP), False Positive (FP), False Negative (FN), True Negative (TN), False Negative (FN) yang ada pada data testing.

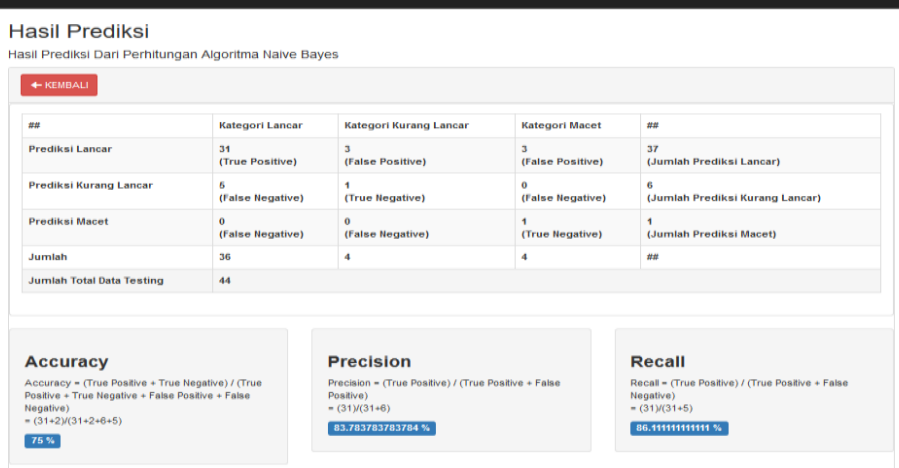

Gambar 9. Halaman Lihat Performance 


\subsection{Pengujian}

\subsubsection{Pengujian Blackbox}

Pengujian blackbox ini bertujuan untuk pengetesan pada setiap fitur yang ada pada aplikasi prediksi kelayakan calon anggota kredit simpan. Berikut merupkan hasil pengetesan seperti tabel 4 berikut:

Tabel 4. Pengujian blackbox

\begin{tabular}{|c|c|c|c|c|}
\hline $\begin{array}{l}\text { Menu Yang } \\
\text { Diuji }\end{array}$ & Pengujian & Input & Output & Keterangan \\
\hline Form login & $\begin{array}{l}\text { Username } \\
\text { Password }\end{array}$ & $\begin{array}{l}\text { Memasukkan } \\
\text { username dan } \\
\text { password }\end{array}$ & $\begin{array}{l}\text { Halaman menu awal } \\
\text { aplikasi muncul }\end{array}$ & Sesuai \\
\hline Menu Utama & $\begin{array}{l}\text { Data Training } \\
\text { Data Testing } \\
\text { Logout }\end{array}$ & $\begin{array}{l}\text { Klik data training } \\
\text { Klik data testing } \\
\text { Klik logout }\end{array}$ & $\begin{array}{l}\text { Masuk data training } \\
\text { Masuk data testing } \\
\text { Keluar dari aplikasi }\end{array}$ & $\begin{array}{l}\text { Sesuai } \\
\text { Sesuai } \\
\text { Sesuai }\end{array}$ \\
\hline $\begin{array}{l}\text { Data } \\
\text { Training }\end{array}$ & $\begin{array}{l}\text { Tambah } \\
\text { Import } \\
\text { Hapus }\end{array}$ & $\begin{array}{l}\text { Klik Tambah } \\
\text { Klik Import } \\
\text { Klik Hapus data }\end{array}$ & $\begin{array}{l}\text { Masuk form tambah data } \\
\text { Halaman upload data set } \\
\text { Data terhapus }\end{array}$ & $\begin{array}{l}\text { Sesuai } \\
\text { Sesuai } \\
\text { Sesuai }\end{array}$ \\
\hline Data Testing & $\begin{array}{l}\text { Tambah } \\
\text { Import } \\
\text { Hapus } \\
\text { Lihat Prediksi }\end{array}$ & $\begin{array}{l}\text { Klik Tambah } \\
\text { Klik Import } \\
\text { Klik Hapus data } \\
\text { Klik lihat prediksi }\end{array}$ & $\begin{array}{l}\text { Masuk form tambah data } \\
\text { Halaman upload data set } \\
\text { Data terhapus } \\
\text { Muncul halaman prediksi }\end{array}$ & $\begin{array}{l}\text { Sesuai } \\
\text { Sesuai } \\
\text { Sesuai } \\
\text { Sesuai }\end{array}$ \\
\hline $\begin{array}{l}\text { Lihat } \\
\text { Prediksi }\end{array}$ & $\begin{array}{l}\text { Detail } \\
\text { Lihat Performance }\end{array}$ & $\begin{array}{l}\text { Klik detail } \\
\text { Klik lihat } \\
\text { performance }\end{array}$ & $\begin{array}{l}\text { Tampil hasil perhitungan } \\
\text { Tampil hasil precision, } \\
\text { accuracy, dan recall. }\end{array}$ & $\begin{array}{l}\text { Sesuai } \\
\text { Sesuai }\end{array}$ \\
\hline
\end{tabular}

\subsubsection{Pengujian Algoritma}

Hasil yang didapat dengan memasukkan 10 data sebagai data training dan 5 data sebagai data testing memperoleh hasil yang sama saat pengujian dengam membandingkan perhitungan manual ataupun dengan perhitungan aplikasi yang dibuat pada penelitian ini. Hasil menunjukkan bahwa aplikasi yang dibuat sudah menerapkan algoritma Nä̈ve Bayes dengan benar.

Pengujian dengan memperhitungkan nilai precision, accuracy maupun recall dengan beberapa tahapan seperti yang ditunjukkan pada tabel 5 . 
Tabel 5. Pengujian precision, accuracy, dan recall

\begin{tabular}{|c|c|c|c|c|}
\hline Data Training & Data Testing & Precision & Accuracy & Recall \\
\hline 50 & 422 & $65 \%$ & $46 \%$ & $55 \%$ \\
\hline 100 & 372 & $65 \%$ & $52 \%$ & $67 \%$ \\
\hline 150 & 372 & $65 \%$ & $54 \%$ & $72 \%$ \\
\hline 200 & 272 & $62 \%$ & $57 \%$ & $87 \%$ \\
\hline 250 & 222 & $78 \%$ & $64 \%$ & $72 \%$ \\
\hline 300 & 172 & $71 \%$ & $68 \%$ & $92 \%$ \\
\hline 350 & 122 & $82 \%$ & $77 \%$ & $91 \%$ \\
\hline $\mathbf{4 7 2}$ & $\mathbf{5 0}$ & $\mathbf{8 2} \%$ & $\mathbf{8 0} \%$ & $\mathbf{9 4} \%$ \\
\hline
\end{tabular}

Pengujian dengan memperhitungkan tingkat ketepatan dapat diketahui bahwa nilai precision, accuracy dan recall cenderung meningkat.

\subsubsection{Analisis Hasil}

Pada aplikasi prediksi kelayakan calon anggota kredit simpan pinjam dengan menggunakan algoritma Naïve Bayes hanya memiliki 1 aktor yaitu pengguna atau admin koperasi. Pada aplikasi ini pengguna diwajibkan untuk login terlebih dahulu untuk dapat mengakses aplikasi. Pengguna dapat melakukan penambahan data, perubahan data dan penghapusan data pada data training maupun data testing. Data yang dimasukkan pada aplikasi ini diantaranya nama, jenis kelamin, umur, jenis pekerjaan, jumlah pinjaman, jangka waktu pengembalian, jaminan, penghasilan, dan kategori. Jika pengguna ingin memprediksi maka pengguna harus melengkapi data-data tersebut agar mendapatkan hasil prediksinya. Hasil prediksi yang ditampilkan bersama dengan proses perhitungannya.

Pengujian yang dilakukan pada aplikasi dengan 2 cara, yaitu pengujian blackbox dan pengujian tingkat precision, accuracy, dan recall. Pada pengujian blackbox hasilnya semua fitur yang terdapat pada aplikasi tersebut dapat berjalan sesuai yang diharapkan pada penelitian ini. Sedangkan pada pengujian tingkat precision memperoleh hasil $84 \%$, tingkat ketepatan accuracy memperoleh hasil 75\% dan tingkat recall memperoleh hasil $86 \%$, hasil yang diperoleh dari perhitungan tersebut cenderung meningkat. Memperolehnya hasil perhitungan tingkat precision, accuracy maupun recall yang semakin meningkat dikarenakan semakin banyak data training yang digunakan maka data pembanding semakin banyak dan hasil yang diperoleh akan semakin akurat.

\section{KESIMPULAN DAN SARAN}

\subsection{Kesimpulan}

Hasil analisis dari aplikasi prediksi kelayakan calon anggota kredit simpan pinjam dapat diambil kesimpulan diantaranya:

1) Aplikasi ini memiliki nilai precision sebesar $82 \%$, nilai accuracy sebesar $80 \%$ dan nilai recall sebesar $94 \%$. Maka aplikasi yang telah dibangun menggunakan algoritma Nä̈ve Bayes telah dapat digunakan.

2) Telah dapat dibangun sebuah aplikasi untuk memprediksi kelayakan calon anggota kredit simpan pinjam dengan menggunakan Nä̈ve Bayes.

3) Proses pengujian pada aplikasi menggunakan 3 metode antara lain: pengujian blackbox 
pengujian algoritma dan pengujian precision, accuracy maupun recall.

\subsection{Saran}

Saran dari aplikasi prediksi kelayakan calon anggota kredit simpan pinjam yaitu untuk penelitian selanjutnya diharapkan dalam menggunakan data training harus diperbanyak untuk mendapatkan hasil yang lebih akurat.

\section{DAFTAR PUSTAKA}

[1] K. Ma’wa, “Analisis Perbandingan Antara Koperasi Simpan Pinjam Dengan Koperasi Jasa Keuangan Syariah Baitul Maal Wa Tamwil," J. Mhs. Fak. Huk., 2013.

[2] T. Mahboob, S. Irfan, and A. Karamat, "A machine learning approach for student assessment in E-learning using Quinlan's C4.5, Naive Bayes and Random Forest algorithms," Proc. 2016 19th Int. MultiTopic Conf. INMIC 2016, 2017.

[3] D. Octabriyantiningtyas, "Adln perpustakaan airlangga," 2016.

[4] A. Jumadi, Z. Arifin, and D. Marisa, "Sistem Pendukung Keputusan Pemberian Kredit Rumah Sejahtera Pada Nasabah Bank Pembangunan Daerah Kalimantan Timur dengan Metode TOPSIS," vol. 3, pp. 156163, 2014.

[5] Y. I. Kurniawan, U. M. Surakarta, and C. Java, "Decision Support System for Acceptance Scholarship With Simple Additive," pp. 99-108, 2015.

[6] Y. S. Nugroho, “Aplikasi Pemrediksi Masa Studi dan Predikat Kelulusan Mahasiswa Informatika Universitas Muhammadiyah Surakarta Menggunakan Metode Naive Bayes," Khazanah Inform., vol. I, no. 1, pp. 29-34, 2015.

[7] A. Jadhav, A. Pandita, A. Pawar, and V. Singh, "Classification of Unstructured Data using Naïve Bayes Classifier and Predictive Analysis for RTI Application," ABHIYANTRIKI An Int. J. Eng. Technol., vol. 3, no. 6, pp. 1-6, 2016.

[8] Y. S. Haryanti, Syarifah Nur , Nugroho, "Perbandingan 3 Metode Dalam Data Mining Untuk Penjurusan Siswa Di SMA N 3 Boyolali," 2015.

[9] Bustami, "Penerapan Algoritma Naive Bayes," J. Inform., vol. 8, no. 1, pp. 884 898, 2014.

[10] V. S and D. S, "Data Mining Classification Algorithms for Kidney Disease Prediction," Int. J. Cybern. Informatics, vol. 4, no. 4, pp. 13-25, 2015. 